\title{
My Child Is God's Gift to Humanity: Development and Validation of the Parental Overvaluation Scale (POS)
}

\author{
Eddie Brummelman \\ Utrecht University
}

\author{
Stefanie A. Nelemans and Bram Orobio de Castro \\ Utrecht University
}

\author{
Sander Thomaes \\ University of Southampton and Utrecht University \\ Brad J. Bushman \\ The Ohio State University and VU University Amsterdam
}

\begin{abstract}
Although it is natural for parents to value their children, some parents "overvalue" them, believing that their own children are more special and more entitled than other children are. This research introduces this concept of parental overvaluation. We developed a concise self-report scale to measure individual differences in parental overvaluation, the Parental Overvaluation Scale (POS; Study 1). The POS has high test-retest stability over 6, 12, and 18 months (Study 2). As demonstrated in a representative sample of Dutch parents (Study 3) and a diverse sample of American parents (Study 4), the POS has an internally consistent single-factor structure; strong measurement invariance across sexes; as well as good convergent, discriminant, and criterion validity. Overvaluation is especially high in narcissistic parents (Studies $3,4,6$ ). When parents overvalue their child, they overclaim their child's knowledge (Study 4), perceive their child as more gifted than actual IQ scores justify (Study 5), want their child to stand out from others, and frequently praise their child in real-life settings (Study 6). By contrast, overvaluation is not consistently related to parents' basic parenting dimensions (i.e., warmth and control) or Big Five personality traits (Studies 3, 4, 6). Importantly, overvalued children are not more intelligent or better performing than other children (Studies 5-6). These findings support the validity of the POS and show that parental overvaluation has important and unique implications for parents' beliefs and practices. Research on overvaluation might shed light on the determinants of parenting practices and the socialization of children's self-views, including narcissism.
\end{abstract}

Keywords: parental overvaluation, parenting, narcissism, praise, positive illusions

A Chinese proverb holds that "there is only one pretty child in the world, and every mother has it." Parents tend to look at their child through rose-colored glasses. However, there are marked individual differences in this tendency. Since the early days of

This article was published Online First November 3, 2014.

Eddie Brummelman, Department of Psychology, Utrecht University; Sander Thomaes, Center for Research on Self and Identity, School of Psychology, University of Southampton, and Department of Psychology, Utrecht University; Stefanie A. Nelemans, Research Centre Adolescent Development, Utrecht University; Bram Orobio de Castro, Department of Psychology, Utrecht University; Brad J. Bushman, School of Communication and Department of Psychology, The Ohio State University, and Department of Communication Science, VU University Amsterdam.

This research was supported by a Fulbright Scholarship to Eddie Brummelman and by The Netherlands Organization for Scientific Research Grant 431-09-022. Study 3 used data of the Longitudinal Internet Studies for the Social Sciences panel administered by CentERdata. We thank Gymnasium Celeanum for participating in our research. We thank Constantine Sedikides and Geertjan Overbeek for their valuable comments on the manuscript.

Correspondence concerning this article should be addressed to Eddie Brummelman, who is now at the Research Institute of Child Development and Education, University of Amsterdam, P.O. Box 15780, 1001 NG Amsterdam, the Netherlands. E-mail: e.brummelman@uva.nl psychology, theorists have noted that some parents hold unrealistically positive, inflated views of their child. For example, Freud (1914/1957) observed that some parents "are under a compulsion to ascribe every perfection to the child - which sober observation would find no occasion to do" (p. 91). Other psychologists have similarly observed that some parents are inclined to perceive their child as an "embryonic genius" (Horney, 1939, p. 91) or "God's gift to man" (Millon, 1969, p. 263). These observations are not just relics of an ancient past. Contemporary child-rearing experts have likewise observed that some present-day parents also perceive their child as exceptional, extraordinary, or perfect (e.g., Twenge, 2006; Young-Eisendrath, 2008).

Yet, this tendency to "overvalue" children has rarely been empirically studied as an individual-difference variable. This is unfortunate, for two reasons. First, such research sheds light on the determinants of parenting practices. When parents believe their children are more special and more entitled than other children, they might treat their children accordingly (Millon, 1969, 2011). As such, overvaluation might have unique implications for parenting practices. Second, overvaluation might cultivate the development of narcissistic traits in children (Otway \& Vignoles, 2006; Thomaes \& Brummelman, in press). Narcissistic children feel superior to others yet need constant external validation. When they are rejected or humiliated, for example, narcissistic children are 
prone to lash out aggressively against others. Narcissism thus represents an important risk factor for youth aggression and violence (Bukowski, Schwartzman, Santo, Bagwell, \& Adams, 2009; Thomaes, Bushman, Stegge, \& Olthof, 2008).

The aim of this research was to develop and validate a measure of parental overvaluation, the Parental Overvaluation Scale (POS), and to explore how overvaluation is related to parenting beliefs and practices. In doing so, we contribute insight into the nature, measurement, and correlates of parental overvaluation and we provide researchers with a tool to study this intriguing and largely overlooked dimension of parents' minds.

\section{Parental Overvaluation}

We define parental overvaluation as parents' belief that their own child is more special and more entitled than other children. The concept of parental overvaluation was first introduced to psychology by Freud (1914/1957). During the decades that followed, other theorists elaborated on the concept (e.g., Millon, 1969, 2011). Although empirical research on parental overvaluation is scarce, there is an abundance of research showing that, in general, people have a tendency to hold positive illusions about their significant others. For example, people often hold positive illusions about their romantic partner's personality (Murray \& Holmes, 1997; Murray, Holmes, \& Griffin, 1996), behavior (Hall \& Taylor, 1976), and physical appearance (Barelds-Dijkstra \& Barelds, 2008).

Preliminary evidence points toward individual differences in parental overvaluation. In two correlational studies (Cohen \& Fowers, 2004; Wenger \& Fowers, 2008), parents rated the degree to which trait adjectives (e.g., "sincere," "dishonest") described their child and "the average child of the same age." A majority of parents rated their own child as having more favorable and fewer unfavorable traits than the average child. This better-than-average effect suggests that parents often overestimate their child's qualities (Alicke, Klotz, Breitenbecher, Yurak, \& Vredenburg, 1995). Importantly, this better-than-average effect was more pronounced for some parents than it was for others, and it was even nonexistent in a minority of them. Another correlational study revealed that some adults, more so than others, believed that their parents overvalued them in their childhood (e.g., "When I was a child, my parents believed I had exceptional talents and abilities"; Otway \& Vignoles, 2006). The fact that some parents hold overly positive views of their child, whereas others hold more realistic views of their child, suggests important individual differences in overvaluation.

\section{Parental Narcissism and Overvaluation}

Of course, not all parents are equally inclined to overvalue their children. We suggest that overvaluation is especially pronounced in parents high in narcissistic traits. Much like Narcissus admired his own image in the water, narcissistic parents may admire their children - their own image of flesh and blood. Early philosophical and psychological writings are consistent with this idea. Kames (1762/1788) noted that "self-love, the most vigorous of all passions, is readily expanded upon children" (p. 71). Similarly, Freud (1914/1957) argued that parents' overvaluation of their children represents "a revival and reproduction of their own narcissism" (p.
91). Clinical observations likewise suggest that narcissistic parents are inclined to use their children as an extension of the self and to ascribe them the wonderful qualities they ascribe themselves $(\mathrm{N}$. W. Brown, 1998; Miller, 1981). Despite its theoretical importance, however, the link between parental narcissism and overvaluation has never been tested empirically.

What might drive narcissistic parents to overvalue their children? Narcissists have a strong desire to be seen as unique, important, and entitled, and they use inventive means to create and maintain their grandiose self-views (Morf \& Rhodewalt, 2001). Given that children are an important part of parents' selves (Aron \& Aron, 1986; Brummelman et al., 2013), overvaluing their child may be an indirect means for narcissistic parents to enhance themselves. Narcissistic parents might believe that their child's traits, behaviors, and accomplishments positively reflect upon themselves, so they may bask in their child's reflected glory (Cialdini et al., 1976). By overvaluing their child, narcissistic parents may indirectly convey to themselves and to others that they are unique and entitled themselves. By analogy, when parents consider their children to be princes and princesses, they imply that they themselves are kings and queens.

\section{Parental Overvaluation and Parenting Practices}

Parents' beliefs guide their actual parenting practices (Darling \& Steinberg, 1993). How, then, does parental overvaluation translate into parenting practices? When parents overvalue their child, they might want to express their inflated views of their child on frequent occasion. As such, overvaluation might lead parents to lavish their child with praise (Millon, 1969, 2011). Praise refers to positive evaluations of the child's traits, behaviors, or accomplishments (Kanouse, Gumpert, \& Canavan-Gumpert, 1981). Parents often believe that children enjoy being praised and that praise is invariably beneficial to children's development (Henderlong \& Lepper, 2002). They often assume, for example, that praise boosts children's self-esteem and motivation (Brummelman, Thomaes, Orobio de Castro, Overbeck, \& Bushman, 2014; Brummelman, Thomaes, Overbeek, et al., 2014; Mueller \& Dweck, 1998). Thus, praise might be a well-accepted and seemingly benign way for overvaluing parents to express their inflated views of their child.

\section{Overview of Present Research}

The first purpose of our research was to develop and validate a concise yet comprehensive self-report measure of parental overvaluation: the Parental Overvaluation Scale (POS; Study 1). We evaluated its test-retest stability in a four-wave longitudinal study (Study 2). Then, we tested its factor structure and its measurement invariance across sexes in a representative sample of Dutch parents (Study 3) and a diverse sample of American parents (Study 4). Measurement invariance indicates that an instrument assesses the same construct in different groups (Vandenberg \& Lance, 2000), and thus represents an important aspect of an instrument's validity. Subsequently, we tested the hypothesis that overvaluation is especially pronounced in parents high in narcissistic traits, who may expand their self-love upon their children (Studies 3, 4, 6). In addition, we tested the hypothesis that overvaluation is associated with parents' tendency to perceive their child as superior to other children, to overclaim their child's knowledge (Study 4), to per- 
ceive their child as more gifted than actual IQ scores justify (Study 5 ), to desire their child to stand out from others, and to frequently praise their child in real-life settings (Study 6). Crucially, we used IQ tests to examine whether overvalued children are objectively more intelligent or better performing than other children (Studies 5-6). Together, these studies provide a stringent examination of the nature, measurement, and correlates of parental overvaluation.

We studied parents of children in late childhood, for two reasons. First, it is a time when pronounced individual differences exist in the extent to which parents hold inflated views of their children. When children are younger, holding overly positive views of them seems more normative for parents, because these views have not yet been tested against reality (Wenger \& Fowers, 2008). For example, young children have not yet started formal schooling, where overvaluing parents' beliefs about their child (e.g., "My child is exceptionally gifted in math") are often challenged by reality (e.g., the child's nonexceptional grade-point average for math). Second, in late childhood, children have acquired the cognitive capacities to evaluate themselves from the perspective of others and to internalize others' views of them (Harter, 2012; Selman, 1980). Thus, from this age, parents' beliefs about them become especially consequential for children's selfviews and behaviors (Collins, Madsen, \& Susman-Stillman, 2002; Maccoby, 1984).

\section{Study 1}

The purpose of Study 1 was to construct the final version of the POS from a large pool of possible items and to explore its factor structure.

\section{Method}

Participants. Participants were 227 parents (69\% mothers, ages $30-55 ; M=42.0, S D=4.6)$ of a child (52\% girls) between 8 and 12 years old $(M=10.2, S D=1.2)$. They were recruited from 10 public elementary schools in the Netherlands. One parent participated per household.

Procedure. The initial item pool consisted of 85 items. All items were dyadic, reflecting parents' overvaluation of a single child. ${ }^{1}$ We constructed these items on the basis of clinical descriptions of parental overvaluation (e.g., Freud, 1914/1957; Kernberg, 1975; Millon, 1969), theories of positive illusions in social perception (e.g., Krebs \& Denton, 1997; Murray et al., 1996), and an existing, retrospective child-report measure of parental overvaluation (Otway \& Vignoles, 2006). We avoided items that were domain specific (e.g., "My child has a natural talent for mathematics") and items that could have a basis in reality (e.g., "My child outperforms his/her classmates in mathematics"). Instead, we generated items that reflected parents' belief that their child is more special (e.g., "My child is more special than other children") and more entitled (e.g., "My child deserves special treatment") than other children. Next, four child development experts indicated which items they considered clearly worded and central to the construct of parental overvaluation. Items mentioned by two or more experts were selected. This resulted in the final item pool, consisting of 53 items. Responses were scored using 4-point scales $(0=$ Not at all true, $1=$ Not really true, $2=$ Sort of true, $3=$ Completely true).

\section{Results and Discussion}

We use two-tailed tests $(\alpha=.05)$ throughout the present article. In order to create a concise and unidimensional scale with nonredundant items, we first selected items with high corrected itemtotal correlations $(r>.50)$ and small to moderate interitem correlations $(.15<r<.50$; Clark \& Watson, 1995). If the correlation between two items was either too weak or too strong, we retained the most clearly worded one. Then, we selected items on theoretical grounds. The four child development experts indicated which remaining items they considered most central to parental overvaluation. Items mentioned by three or more experts were selected. This resulted in the final set of seven items constituting the POS (see Appendix A). Responses were averaged across items (Cronbach's $\alpha=.80 ; M=0.94, S D=0.54$ ). Examination of retained and deleted items indicated that no aspect of overvaluation was lost in the selection process. In fact, the POS correlated strongly with the averaged score on the deleted items, $r(225)=.85, p<$ .001 .

To examine the factor structure of the POS, we conducted an exploratory factor analysis (maximum likelihood extraction, direct oblimin rotation; Costello \& Osborne, 2005). On the basis of inspection of the scree plot and a criterion eigenvalue of 1 , results revealed a single-factor solution (eigenvalue $=3.21$, explained variance $=46 \%$ )

In this study, as well as in Studies 3 and 4, we conducted confirmatory factor analysis (CFA) using Mplus version 7.11 (L. K. Muthén \& Muthén, 2012). Because items were measured on 4-point scales, we treated them as categorical variables and used robust weighted least squares estimation (L. K. Muthén \& Muthén, 2012). We allowed error variances between items to covary if the modification indices implied that adding this covariance would significantly increase model fit. All modifications were made simultaneously.

Model fit was assessed with the Tucker-Lewis index (TLI), comparative fit index (CFI), and the root-mean-aquare error of approximation (RMSEA) with a $90 \%$ confidence interval (CI). TLI and CFI values $\geq .90$ and RMSEA values $\leq .08$ indicate acceptable model fit, whereas TLI and CFI values $\geq .95$ and RMSEA values $\leq .06$ indicate good model fit (these cutoffs are based on Hu \& Bentler, 1999; Kline, 2005; B. O. Muthén, 2004).

A CFA confirmed that the unconditional one-factor model showed acceptable-to-good model fit, $\chi^{2}(11)=23.36, \mathrm{CFI}=.987$, $\mathrm{TLI}=.976, \mathrm{RMSEA}=.070,90 \%$ CI $[.029, .110]$. Standardized factor loadings of this one-factor model ranged from .60 to .75 (see Table 1).

Together, these results demonstrate that the POS has an internally consistent single-factor structure.

\footnotetext{
${ }^{1}$ Parents often favor one child over their other children (Suitor, Sechrist, Plikuhn, Pardo, \& Pillemer, 2008). To prevent this from affecting our findings, we ensured that parents reported about a single child who they did not "select" themselves. In Studies 1, 2, 5 and 6, parents were recruited through their child, and they reported about this child. In Studies 3 and 4 parents were recruited directly on the condition that they had a child between 8 and 12 years old. If they had multiple children this age, one was randomly selected (i.e., parents reported about the one who most recently had his or her birthday).
} 
Table 1

Standardized Factor Loadings in Confirmatory Factor Analyses of POS Items in Studies 1, 3, and 4

\begin{tabular}{cccc}
\hline POS item & $\begin{array}{c}\text { Study 1 } \\
(N=227)\end{array}$ & $\begin{array}{c}\text { Study 3 } \\
(N=388)\end{array}$ & $\begin{array}{c}\text { Study 4 } \\
(N=250)\end{array}$ \\
\hline Item 1 & 0.62 & 0.59 & 0.37 \\
Item 2 & 0.65 & 0.78 & 0.65 \\
Item 3 & 0.63 & 0.61 & 0.41 \\
Item 4 & 0.67 & 0.53 & 0.44 \\
Item 5 & 0.75 & 0.73 & 0.83 \\
Item 6 & 0.60 & 0.87 & 0.73 \\
Item 7 & 0.73 & 0.58 & 0.44 \\
\hline
\end{tabular}

Note. $\quad$ POS $=$ Parental Overvaluation Scale.

\section{Study 2}

The purpose of Study 2 was to investigate the test-retest stability of the POS over short-term (6 months), medium-term (12 month), and long-term (18 months) time intervals.

\section{Method}

Participants. Participants were 415 mothers (ages 28-60 years, $M=42.2, S D=4.0$ ) and 289 fathers (ages 29-64 years, $M=44.6, S D=4.6)$ of a child ( $53 \%$ girls) between 7 and 12 years old $(M=9.5, S D=0.9)$. They were recruited via 17 elementary schools in the Netherlands. Data were collected as part of a larger longitudinal project.

Procedure. Participants completed the POS four times, with 6-month intervals between each completion. Parents who had multiple children between 7 and 12 years old completed the POS for each of these children individually, yielding a total of 476 and 334 unique reports from mothers and fathers, respectively.

\section{Results and Discussion}

Because some mothers and fathers reported about the same child, data for mothers and fathers were analyzed separately. As can be seen in Table 2, the test-retest stability was high ( $r \mathrm{~s}=$ $.56-.80, p s<.001)$ across 6,12 , and 18 months, for both fathers and mothers. Thus, the POS assesses relatively stable and enduring individual differences in parental overvaluation.

\section{Study 3}

Study 3 had three purposes. First, we wanted to replicate the factor structure of the POS in a representative sample of Dutch parents. Second, we wanted to test the measurement invariance of the POS across child and parent sex. We expected the single-factor structure to hold similarly for boys and girls, and for fathers and mothers. Third, we wanted to assess the link between overvaluation and parents' inflated, narcissistic self-views. We expected parental overvaluation to be higher among more narcissistic parents.

\section{Method}

Participants. Participants were 388 parents (56\% mothers, ages 27-69 years, $M=42.3, S D=5.5)$ of a child (51\% girls) between 8 and 12 years old $(M=10.2, S D=1.4)$. On the basis of having a child this age, parents were randomly selected from 5,000 Dutch households participating in the Longitudinal Internet Studies for the Social Sciences panel, which is based on a probability sample of households in the Netherlands.

Procedure. Participants completed the POS (Cronbach's $\alpha=$ $.81, M=1.27, S D=0.55)$. Narcissism was assessed using the 16-item Narcissistic Personality Inventory-16 (Ames, Rose, \& Anderson, 2006): For each item, participants chose which of two statements best described themselves (e.g., "I think I am a special person" vs. "I am no better or nor worse than most people"; "I am apt to show off if I get the chance" vs. "I try not to be a show off"). The total score was the proportion (range $=0-1$ ) of narcissistic responses (Cronbach's $\alpha=.76 ; M=0.20, S D=0.18$ ).

\section{Results}

Preliminary analyses. Skewness $(0.23, S E=0.12)$ and kurtosis $(0.69, S E=0.25)$ estimates indicate adequate normality for the POS.

Narcissism. As predicted, parental overvaluation was positively correlated with parental narcissism, $r(386)=.22, p<.001$.

CFAs. A CFA showed that the unconditional one-factor model showed good model fit, $\chi^{2}(8)=16.55, \mathrm{CFI}=.996$, TLI $=.990$, RMSEA $=.052,95 \%$ CI $[.013, .088]$. Standardized factor loadings of this one-factor model ranged from .53 to .87 (see Table 1).

Measurement invariance analyses. In this study and in Study 4, which uses a diverse sample of American parents, we examined the measurement invariance between boys and girls and between fathers and mothers. We tested configural, metric, and scalar invariance in a stepwise manner.

1. Configural invariance means that the same subset of items loads on the same construct (i.e., latent factor) in different groups. For this, we examined whether an unconstrained model (baseline model $\mathrm{M}_{0}$, in which factor loadings and thresholds were freely

Table 2

Descriptive Statistics and Test-Retest Stability of POS Across Four Six-Monthly Waves in Study 2

\begin{tabular}{cccccccc}
\hline & & \multicolumn{7}{c}{ Zero-order correlations } \\
\cline { 5 - 8 } Variable & $M$ & $S D$ & Cronbach's $\alpha$ & $\mathrm{T} 1$ & $\mathrm{~T} 2$ & $\mathrm{~T} 3$ & $\mathrm{~T} 4$ \\
\hline & & \multicolumn{7}{c}{ Fathers $(n=334)$} & & & \\
T1 & 1.30 & 0.50 & .75 & - & & \\
T2 & 1.29 & 0.53 & .81 & 0.64 & - & & \\
T3 & 1.26 & 0.56 & .84 & 0.61 & 0.80 & - & \\
T4 & 1.18 & 0.51 & .84 & 0.56 & 0.78 & 0.79 & - \\
\hline & & & Mothers $(n=476)$ & & & \\
T1 & 1.16 & 0.53 & .80 & - & & & \\
T2 & 1.12 & 0.50 & .81 & 0.72 & - & & \\
T3 & 1.12 & 0.51 & .82 & 0.72 & 0.79 & - & \\
T4 & 1.12 & 0.50 & .81 & 0.67 & 0.72 & 0.78 & - \\
\hline
\end{tabular}

Note. All zero-order correlations are significant at $p<.001$. Cronbach's $\alpha$ was calculated in SPSS. All other estimates were calculated using Mplus v.7.11 using full information maximum likelihood. Each wave (T1-T4) was separated by 6 months. POS $=$ Parental Overvaluation Scale; T1$\mathrm{T} 4$ = Time 1-Time 4. 
estimated between groups) fits well in both groups separately. A well-fitting model for both groups would indicate configural invariance.

2. Metric invariance means that the strength of the associations between items and the latent factor (i.e., the factor loadings) are similar for different groups. For this, we compared the baseline model $\left(\mathrm{M}_{0}\right)$ with a model in which the factor loadings of the items on the latent factor were constrained to be equal across the two groups $\left(M_{1}\right)$. No significant difference in model fit between $M_{0}$ and $\mathrm{M}_{1}$ would indicate metric invariance.

3. Scalar invariance means that not only the strength of the associations between items and their underlying construct (i.e., the factor loadings) but also the item thresholds (i.e., item intercepts for categorical variables) are similar for different groups. For this, we compared the metric model $\left(\mathrm{M}_{1}\right)$ with a model in which the thresholds of the items were also constrained to be equal between the two groups $\left(\mathrm{M}_{2}\right)$. No significant difference in model fit between $\mathrm{M}_{1}$ and $\mathrm{M}_{2}$ would indicate scalar invariance.

No significant difference in model fit between $\mathrm{M}_{0}$ and $\mathrm{M}_{1}$ and between $M_{1}$ and $M_{2}$ would indicate strong measurement invariance (i.e., that the POS assesses the same construct in boys and girls and in fathers and mothers).

We first estimated the CFA model in boys and girls separately. The one-factor model showed good model fit for boys and acceptable-to-good model fit for girls (see Table 3). We then tested for configural, metric, and scalar invariance between boys and girls. All models showed acceptable-to-good fit to the data (see Table 4). Importantly, chi-square difference tests (L. K. Muthén \& Muthén, 2012) revealed no significant differences in model fit between the configural and metric model $(p=.20)$, and between the metric and scalar model $(p=.09)$. Thus, the one-factor model showed strong measurement invariance between boys and girls.

We also estimated the CFA model in fathers and mothers separately. The one-factor model showed good model fit for fathers and acceptable-to-good model fit for mothers (see Table 3). We then tested for configural, metric, and scalar invariance between fathers and mothers. All models showed acceptable-to-good

Table 3

Confirmatory Factor Analyses of POS per Child and Parent Sex in Studies 3 and 4

\begin{tabular}{lcccc}
\hline \multicolumn{1}{c}{ Variable } & \multicolumn{1}{c}{$\chi^{2}(d f)$} & CFI & TLI & RMSEA [90\% CI $]$ \\
\hline \multicolumn{5}{c}{ Study 3} \\
Boys $(n=192)$ & $17.27(11)$ & .994 & .989 & $.054[.000, .101]$ \\
Girls $(n=196)$ & $28.29(12)$ & .986 & .976 & $.083[.043, .123]$ \\
Fathers $(n=171)$ & $12.36(11)$ & .999 & .997 & $.027[.000, .087]$ \\
Mothers $(n=217)$ & $26.87(11)$ & .987 & .975 & $.082[.043, .121]$ \\
\hline \multicolumn{5}{c}{ Study 4} \\
Boys $(n=143)$ & $18.22(12)$ & .985 & .974 & $.060[.000, .113]$ \\
Girls $(n=105)$ & $20.31(13)$ & .960 & .936 & $.073[.000, .132]$ \\
Fathers $(n=124)$ & $30.13(12)$ & .960 & .930 & $.110[.062, .160]$ \\
Mothers $(n=125)$ & $21.52(14)$ & .960 & .940 & $.066[.000, .118]$ \\
\hline
\end{tabular}

Note. In Study 4, one parent failed to state his or her own sex, and two parents failed to state their child's sex. POS $=$ Parental Overvaluation Scale; $\mathrm{CFI}=$ comparative fit index; TLI $=$ Tucker-Lewis index; RMSEA $=$ root-mean-square error of approximation; $\mathrm{CI}=$ confidence interval.
Table 4

Measurement Invariance Tests of POS Between Child and

Parent Sexes in Studies 3 and 4

\begin{tabular}{lcccc}
\hline \multicolumn{1}{c}{ Variable } & \multicolumn{1}{c}{$\chi^{2}$} & CFI & TLI & $\begin{array}{c}\text { RMSEA } \\
{[90 \% \text { CI }]}\end{array}$ \\
\hline & Study 3 & & & \\
$\begin{array}{l}\text { Boys-Girls }(N=388) \\
\text { Configural invariance }\end{array}$ & $45.63(23)$ & .990 & .982 & $.071[.040, .101]$ \\
$\begin{array}{l}\text { Metric invariance } \\
\text { Scalar invariance }\end{array}$ & $51.27(29)$ & .990 & .986 & $.063[.033, .091]$ \\
Fathers-Mothers $(N=388)$ & $68.87(42)$ & .988 & .988 & $.057[.031, .081]$ \\
$\quad$ Configural invariance & $38.51(22)$ & .993 & .986 & $.062[.027, .094]$ \\
Metric invariance & $44.26(28)$ & .993 & .989 & $.055[.019, .084]$ \\
Scalar invariance & $62.18(41)$ & .990 & .990 & $.052[.022, .076]$ \\
\hline & Study 4 & & & \\
& & & & \\
Boys-Girls $(n=248)$ & $38.54(25)$ & .978 & .963 & $.066[.014, .105]$ \\
$\quad$ Configural invariance & $43.53(31)$ & .980 & .973 & $.057[.000, .094]$ \\
$\quad \begin{array}{l}\text { Metric invariance } \\
\text { Scalar invariance }\end{array}$ & $57.71(44)$ & .978 & .979 & $.050[.000, .083]$ \\
Fathers-Mothers $(n=249)$ & & & & \\
$\quad$ Configural invariance & $49.87(26)$ & .963 & .941 & $.086[.049, .122]$ \\
$\quad \begin{array}{l}\text { Metric invariance } \\
\text { Scalar invariance }\end{array}$ & $50.81(32)$ & .971 & .962 & $.069[.029, .103]$ \\
\hline
\end{tabular}

Note. $\mathrm{POS}=$ Parental Overvaluation Scale; $\mathrm{CFI}=$ comparative fit index; TLI $=$ Tucker-Lewis index; RMSEA $=$ root-mean-square error of approximation; $\mathrm{CI}=$ confidence interval

fit to the data (see Table 4). Importantly, chi-square difference tests (L. K. Muthén \& Muthén, 2012) revealed no significant differences in model fit between the configural and metric model $(p=.22)$, and between the metric and scalar model $(p=.11)$ Thus, the one-factor model showed strong measurement invariance between fathers and mothers.

\section{Discussion}

Together, these findings confirm, in a representative sample of Dutch parents, the single-factor structure of the POS. Also, they demonstrate strong measurement invariance of this factor between boys and girls, and between fathers and mothers. In addition, the findings show that overvaluation is especially high in narcissistic parents.

\section{Study 4}

In Study 4, we sought to corroborate the factor structure and measurement invariance of the POS in a diverse sample of American parents. In addition, we attempted to replicate in Study 4 the finding that overvaluation is related to parents' level of narcissism and examined whether this relationship is unique to narcissism or holds for other positive self-views as well (i.e., self-esteem).

Importantly, we also explored in Study 4 the discriminant and convergent validity of the POS. We had no a priori expectations about the association between parental overvaluation and parents' basic parenting dimensions (i.e., warmth and control) and Big Five personality traits. However, we expected overvaluation to be associated with parents' tendency to perceive their child as superior to others and to overestimate their child's capacities.

We developed an objective method to assess parents' overestimation of their child's capacities. Building on the Overclaiming 
Technique (Paulhus, Harms, Bruce, \& Lysy, 2003), we presented parents with multiple terms that children should be familiar with by the end of sixth grade (e.g., "Anne Frank"). Parents indicated to what extent their child is familiar with each term. Crucially, we included terms that did not actually exist (e.g., "Queen Alberta"). When parents claim their child to be familiar with nonexisting terms, they "overclaim" their child's knowledge. We expected this tendency to be especially high in parents who overvalue their child.

\section{Method}

Participants. Participants were 250 parents (50\% mothers, ages 24-74 years, $M=41.7, S D=10.1)$ of a child (42\% girls) between 8 and 12 years old $(M=10.0$ years, $S D=1.4)$. They were recruited via Qualtrics panel management and were a diverse sample of American parents who were matched on age and race/ ethnicity with the U.S. population in the 2010 census.

Procedure. As in Study 3, participants completed the POS (Cronbach's $\alpha=.72, M=1.69, S D=0.54$ ) and the Narcissistic Personality Inventory-16 (Cronbach's $\alpha=.84, M=0.31, S D=$ 0.24). In addition, they completed measures of self-esteem, the Big Five personality traits, perceived superiority, overclaiming, parental warmth, and parental control.

Self-esteem. Self-esteem was measured using the 10-item (e.g., "On the whole, I am satisfied with myself" and "I feel that I have a number of good qualities"; from $0=$ Strongly disagree to 6 = Strongly agree) Self-Esteem Scale (Rosenberg, 1965; Cronbach's $\alpha=.88, M=2.17, S D=0.55$ ).

Big Five personality traits. The Big Five personality traits were assessed using the Ten-Item Personality Inventory (Gosling, Rentfrow, \& Swann, 2003). For each personality trait, participants indicated how strongly a pair of traits described them (e.g., extraverted and enthusiastic for Extraversion; from $0=$ Disagree strongly to $6=$ Agree strongly). Responses were averaged across items: Extraversion $(M=3.06, S D=1.41)$, Agreeableness $(M=$ $4.14, S D=1.12)$, Conscientiousness $(M=4.58, S D=1.15)$, Emotional Stability $(M=3.75, S D=1.31)$, and Openness to Experience $(M=4.06, S D=1.17)$.

Perceived superiority. Perceived superiority of the child was assessed using the My Child Versus Other Children Scale (see Appendix B). We developed this measure for this study by adapting the Self Versus Other Scale (Campbell, Bonacci, Shelton, Exline, \& Bushman, 2004). Participants were presented seven images, each consisting of one "my child" circle and three "other children" circles. The relative size of the "my child" circle gradually increased from the first image (where "my child" is smaller than other children), to the fourth image (where "my child" is the same size as other children), to the seventh image (where "my child" is larger than other children). Participants selected the image that best reflected how they perceive their child compared with other children, with higher numbers indicating higher perceived superiority of their child over other children $(M=4.70, S D=$ 1.37).

Overclaiming. Overclaiming was assessed using the Parental Overclaiming Questionnaire (see Table C1), an extension of the Over-Claiming Questionnaire (Paulhus et al., 2003) that we developed for this study. Participants were presented with 80 terms covering four different topics (i.e., historical events, historical figures, world geography, and literature), taken from The New First Dictionary of Cultural Literacy (Hirsch, 2004), a dictionary containing all terms that a child should be familiar with by the end of sixth grade (sample items: "World War I," "Anne Frank," "Berlin," and "The Wonderful Wizard of Oz"). Participants estimated their child's familiarity with each term $(0=$ Never heard of it, 1 = Little familiar, 2 = Somewhat familiar, 3 = Quite familiar, 4 = Very familiar). However, 20 of these terms were foils-they did not actually exist (sample foils: "Storming of Austria," "Queen Alberta," "The Green Sea," and "The Princess and the Grapes").

By definition, any degree of claimed knowledge of foils (i.e., false alarm) indicates overclaiming of the child's knowledge. However, using only false alarms to index overclaiming is limited, because people who overclaim should do so on foils as well as on targets (Paulhus et al., 2003). Signal detection formulas overcome this limitation by taking into account all responses, on foils as well as on targets. Signal detection theory holds that participants' responses reflect two factors: response bias (i.e., the general tendency to respond "yes" or "no") and sensitivity (i.e., the ability to discriminate between targets and foils; Macmillan \& Creelman, 2005). Response bias indicates overclaimed knowledge, whereas sensitivity indicates accurately reported knowledge. We indexed response bias using the criterion location (c) formula (reverse scored to indicate the general tendency to respond "yes" rather than "no"), and sensitivity using the $d$ prime $\left(d^{\prime}\right)$ formula (Paulhus et al., 2003; Stanislaw \& Todorov, 1999). ${ }^{2}$ The formulas were applied to each of four cutoffs on the rating scale (i.e., $0-1,1-2$, $2-3,3-4)$, and the resulting values were averaged across cutoffs. Results were similar for each cutoff and each topic.

Parental warmth. Parental warmth was measured using the eight-item (e.g., "I am really interested in what my child does" and "I let my child know I love him/her"; from $0=$ Almost never true to $3=$ Almost always true) Warmth subscale of the Short Form of the Parental Acceptance-Rejection Questionnaire (Rohner, 2005a). Responses were averaged across items (Cronbach's $\alpha=.87, M=$ 2.73, $S D=0.35$ ).

Parental control. Parental control was measured using the 13-item (e.g., "I see to it that my child knows exactly what (s)he may or may not do" and "I insist that my child must do exactly as (s)he is told"; from $0=$ Almost never true to $3=$ Almost always true) Parental Control Scale (Rohner, 2005b). Responses were averaged across items (Cronbach's $\alpha=.66, M=2.12, S D=$ $0.35)$.

\section{Results}

Correlations between the study's main variables are displayed in Table 5.

CFAs. A CFA showed that the unconditional one-factor model showed good model fit, $\chi^{2}(11)=19.02$, CFI $=.987$, TLI $=$

\footnotetext{
${ }^{2}$ Both formulas are calculated on the basis of false-alarm rate (i.e., the proportion of foils on which participants gave a rating above the cutoff) and hit rate (i.e., the proportion of real items on which participants gave a rating above the cutoff). Because the formulas cannot deal with values of 0 or 1 , values of 0 are replaced with $0.5 / 20$ (with 20 being the number of foils) for false-alarm rates and with $0.5 / 60$ (with 60 being the number of targets) for hit rates, whereas values of 1 are replaced with $(20-0.5) / 20$ for false-alarm rates and with (60-0.5)/60 for hit rates (Macmillan \& Kaplan, 1985; Stanislaw \& Todorov, 1999).
} 
Table 5

Zero-Order Correlations Among Main Variables in Study 3

\begin{tabular}{|c|c|c|c|c|c|c|c|c|c|c|c|c|c|}
\hline Measure & $n$ & 1 & 2 & 3 & 4 & 5 & 6 & 7 & 8 & 9 & 10 & 11 & 12 \\
\hline 1. Parental overvaluation & 250 & - & & & & & & & & & & & \\
\hline 2. Perceived superiority & 249 & $.26^{* * * *}$ & - & & & & & & & & & & \\
\hline 3. Overclaiming & 249 & $.29^{* * * *}$ & -.07 & - & & & & & & & & & \\
\hline 4. Accuracy & 249 & .07 & .07 & $.26^{* * * *}$ & - & & & & & & & & \\
\hline 5. Narcissism & 248 & $.37^{* * * *}$ & $.21^{* * * * *}$ & $.27^{* * * *}$ & .06 & - & & & & & & & \\
\hline 6. Self-esteem & 247 & .03 & .12 & .07 & $.32^{* * * * *}$ & $.14^{*}$ & - & & & & & & \\
\hline 7. Extraversion & 246 & $.18^{* * *}$ & $.17^{* * *}$ & $.24^{* * * *}$ & $.24^{* * * *}$ & $.43^{* * * *}$ & $.38^{* * * *}$ & - & & & & & \\
\hline 8. Agreeableness & 246 & -.02 & .05 & -.04 & $.20^{* *}$ & $-.23^{* * * *}$ & $.21^{* * * *}$ & -.08 & - & & & & \\
\hline 9. Conscientiousness & 246 & -.03 & -.03 & -.11 & $.22^{* * * *}$ & .03 & $.40^{* * * *}$ & $.15^{*}$ & $.30^{* * * *}$ & - & & & \\
\hline 10. Emotional Stability & 246 & -.03 & .01 & .03 & $.19^{* * *}$ & -.08 & $.45^{\text {***** }}$ & $.13^{*}$ & $.31^{* * * *}$ & $.37^{* * * *}$ & - & & \\
\hline 11. Openness to Experience & 246 & .06 & $.14^{*}$ & .10 & $.28^{* * * *}$ & $.24^{* * *}$ & $.38^{* * * *}$ & $.51^{* * *}$ & $.21^{* * * *}$ & $.26^{* * * *}$ & $.20^{* * *}$ & - & \\
\hline 12. Warmth & 248 & $.14^{*}$ & .12 & $.17^{* *}$ & $.18^{* *}$ & .11 & $.40^{* * * *}$ & $.23^{* * * *}$ & $.26^{* * * *}$ & $.20^{* *}$ & $.18^{* * *}$ & $.29^{* * * *}$ & - \\
\hline 13. Control & 249 & .09 & .02 & -.05 & .06 & -.04 & $.17^{* *}$ & .01 & .08 & $.15^{*}$ & .09 & -.02 & $.13^{*}$ \\
\hline
\end{tabular}

Note. $\quad N=250$. There were a few missing values $(n=0-4$ per variable) because a few participants dropped out over the course of questionnaire completion.

${ }^{*} p<.05 .{ }^{* *} p<.01 .^{* * *} p<.001$.

.975, RMSEA $=.054,90 \%$ CI $[.000, .094]$. Standardized factor loadings of this one-factor model ranged from .37 to .73 (see Table $1)$.

Measurement invariance analyses. We first estimated the CFA model in boys and girls separately. The one-factor model showed good model fit for boys and acceptable-to-good model fit for girls (see Table 3). We then tested for configural, metric, and scalar invariance between boys and girls. All models showed acceptable-to-good fit to the data (see Table 4). Importantly, chi-square difference tests (L. K. Muthén \& Muthén, 2012) revealed no significant differences in model fit between the configural and metric model $(p=.31)$, and between the metric and scalar model $(p=.26)$. Thus, the one-factor model showed strong measurement invariance between boys and girls.

We also estimated the CFA model in fathers and mothers separately. The one-factor model showed acceptable-to-good model fit for both fathers and mothers (see Table 3). We then tested for configural, metric, and scalar invariance between fathers and mothers. All models showed acceptable-to-good fit to the data (see Table 4). Importantly, chi-square difference tests (L. K. Muthén \& Muthén, 2012) revealed no significant differences in model fit between the configural and metric model $(p=.53)$, and between the metric and scalar model $(p=.36)$. Thus, the onefactor model showed strong measurement invariance between fathers and mothers. ${ }^{3}$

Preliminary analyses. Skewness $(.02, S E=0.15)$ and kurtosis $(-.16, S E=0.31)$ estimates indicate adequate normality for the POS.

Personality and parenting. Replicating Study 3, overvaluation was positively related to parental narcissism, $r(246)=.37$, $p<.001$. Extending Study 3, overvaluation was unrelated to parental self-esteem, $r(245)=.03, p=.654$. Also extending Study 3 , overvaluation was largely unrelated to basic parenting dimensions and Big Five personality traits. In particular, overvaluation was unrelated to parental control, Conscientiousness, Emotional Stability, Openness to Experience, and Agreeableness $(|.02|<r s<$ $|.09|, p \mathrm{~s}>$.168). It was positively related to parental warmth and Extraversion, $r(246)=.14, p=.028$; and, $r(244)=.18, p=.005$, respectively, but these relationships became nonsignificant when narcissism was controlled for, $t(243)=1.78, p=.076, b=0.08$, $\beta=.12$; and, $t(243)=0.34, p=.737, b=0.06, \beta=.02$, respectively.

Perceived superiority. Overvaluation was related to parents' tendency to perceive their child as superior to other children (i.e., parents who overvalue their child see their child as "bigger" than other children), $r(247)=.26, p<.001$. This relationship remained significant even when narcissism, self-esteem, Big Five traits, and parenting dimensions (warmth, control) were controlled for, $t(232)=2.90, p=.004, b=0.51, \beta=.20$.

Overclaiming. Crucially, overvaluation was also related to parents' overclaiming of their child's knowledge, $r(247)=.29$, $p<.001$ : Parents who overvalue their child often claim their child to have knowledge of many different topics, including topics that do not exist. By contrast, overvaluation was unrelated to parents' accurately reported knowledge of their child, $r(247)=.07, p=$ .256. The relationship between overvaluation and overclaiming remained significant even when narcissism, self-esteem, Big Five traits, parenting dimensions (warmth, control), and accurately reported knowledge were controlled for, $t(231)=2.91, p=.004$, $b=0.28, \beta=.19$. This constitutes the first behavioral evidence that overvaluing parents actively overclaim their child's qualities.

\section{Discussion}

These findings corroborate, in a diverse sample of American parents, the factor structure of the POS and its measurement invariance between boys and girls and between fathers and mothers. Study 4 extends Study 3 in three important ways. First, it

\footnotetext{
${ }^{3}$ Given that the POS has strong measurement invariances across sexes, we can interpret sex differences in overvaluation. We combined data from all studies $(N=1,757$, using only Wave 1 of Study 2$)$ and found that overvaluation did not differ between boys $(M=1.28, S D=0.58)$ and girls $(M=1.23, S D=0.56)(t=1.48, p=.140, d=0.07,95 \%$ CI $[-0.02$, $0.17])$, but was higher in fathers $(M=1.36, S D=.56)$ than mothers $(M=$ $1.18, S D=.56)(t=6.42, p<.001, d=0.32,95 \%$ CI $[0.22,0.42])$. Although contrary to common belief, the latter finding might result from men placing higher value on standing out from others than women do (Trapnell \& Paulhus, 2012).
} 
demonstrates that parental overvaluation is associated with parents' tendency to perceive their child as superior to others and to overclaim their child's capacities. Importantly, overvaluation was not associated with parents' accurate reports of their child's knowledge. Second, this study demonstrates that parental overvaluation is largely unrelated to basic parenting dimensions (i.e., warmth, control) and Big Five personality traits. Overvaluation was related to parental warmth and Extraversion: Parents who overvalue their child appeared to be somewhat more affectionate and outgoing than other parents. But because these relationships were unexpected and small in size, we attempted to replicate them in Study 6. Third, Study 4 shows that parental overvaluation is unrelated to parental self-esteem but is positively related to narcissism, attesting to the specificity of the overvaluation-narcissism link.

\section{Study 5}

Study 4 shows that overvaluation is associated with parents' inclination to "overclaim" their child's knowledge. An important question is whether this finding generalizes to other domains and to other measures of overestimation of the child's abilities. In Study 5, we used a "discrepancy method," where parents' beliefs are compared with an objective criterion (Paulhus \& Holden, 2010). We examined whether parental overvaluation is associated with parents' views of their child as gifted above and beyond an objective criterion-children's actual IQ scores. We also examined whether overvalued children are more intelligent than other children.

\section{Method}

Participants. Participants were 82 parents (74\% mothers, ages 33-63 years, $M=44.90, S D=4.93)$ and their child $(46 \%$ girls) between 11 and 13 years old $(M=12.53, S D=0.45)$. They were recruited via a gymnasium secondary school in the Netherlands (comparable to a public university-preparatory school in the United States). All children received active parental consent and provided assent.

Procedure. Parents completed the POS (Cronbach's $\alpha=.70$, $M=1.11, S D=0.46)$ and three items indexing the perceived giftedness of their child (e.g., "I see my child as gifted"; from $0=$ Not at all true to $4=$ Completely true; Cronbach's $\alpha=.96, M=$ $1.84, S D=1.31$ ). Under supervision of a trained assistant, children completed a standardized Dutch intelligence test-the Dutch Intelligence Test for Educational Level (Nederlandse Intelligentietest voor Onderwijsniveau; van Dijk \& Tellegen, 2004). We obtained children's total intelligence score $(M=119.52, S D=$ 11.37).

\section{Results and Discussion}

Correlations were as predicted: Overvaluation was positively correlated with perceived giftedness, $r(80)=.25, p=.027$, but was unrelated to actual intelligence, $r(80)=-.06, p=.596$. Perceived giftedness was positively correlated with actual intelligence, $r(80)=.24, p=.033$. As the most stringent test of our hypothesis: Overvaluation was positively correlated with perceived giftedness even when actual intelligence was controlled for, $t(79)=2.46, p=.016, b=.74, \beta=.26$.
Thus, Study 5 provides a conceptual replication of Study 4 and shows that overvaluation is associated with parents' perceptions of their child as more gifted than actual IQ scores justify. In addition, this study demonstrates that overvalued children are not more intelligent than other children.

\section{Study 6}

Study 6 had four aims. The first and most important aim was to examine how overvaluation is related to actual parenting practices. We addressed this question by conducting in-home observations of parent-child interactions. We examined whether overvaluation is associated with parental praise. Parents were observed while they were administering mathematics exercises to their child-a prototypical performance context for elementary school-age children. Praise was operationalized as spoken positive evaluations of the child (Henderlong \& Lepper, 2002; Kanouse et al., 1981). We also measured children's actual performance on the mathematics exercises.

In addition, Study 6 aimed to provide a novel behavioral test of the idea that parents who overvalue their child often want their child to stand out from the crowd. One way to accomplish this is by giving their children unique, uncommon names (Twenge, Abebe, \& Campbell, 2010; Varnum \& Kitayama, 2011). Naming practices provide a window into the values that parents adhere to (Finch, 2008). By giving their child a name that very few other children have, parents may express the value of standing out from others. We therefore expected parents who overvalue their children to have children with more unique, uncommon names.

Another aim was to explore the possibility that overvalued children have certain basic temperamental characteristics that make them more likely to be overvalued by their parents. For this purpose, we assessed children's behavioral inhibition and activation, which are considered the motivational building blocks of personality (e.g., Elliot \& Thrash, 2002; Rothbart, Ahadi, \& Evans, 2000). For example, behavioral activation is believed to be central to extraversion (Depue \& Collins, 1999; Elliot \& Thrash, 2002; Rothbart et al., 2000). We had no a priori expectations about the association between parental overvaluation and children's basic temperamental characteristics.

An additional aim of Study 6 was to replicate the link between overvaluation and narcissism, basic parenting dimensions, and Big Five personality traits.

\section{Method}

Participants. Participants were 103 parents (88\% mothers, ages 30-62 years, $M=43.4, S D=4.1)$ and their child ( $51 \%$ girls) between 7 and 11 years old $(M=8.9, S D=0.9) .{ }^{4}$ They were randomly selected from the sample described in Study 2. All parents provided active informed consent for their child to participate (parental consent rate $=56 \%$ ), and children assented themselves (assent rate $=100 \%$ ).

Procedure. Several days before the in-home observation, parents completed the POS (Cronbach's $\alpha=.73, M=1.20, S D=$

\footnotetext{
${ }^{4}$ One hundred twenty parents participated in the in-home observations. However, data of four participants were lost due to camera failure, and 13 participants did not complete the POS.
} 
0.48), the Narcissistic Personality Inventory-16 (Cronbach's $\alpha=$ .69, $M=0.24, S D=0.17$ ), the Rosenberg Self-Esteem Scale (Cronbach's $\alpha=.86, M=2.47, S D=0.45$ ), the Warmth subscale of the Short Form of the Parental Acceptance-Rejection Questionnaire (Cronbach's $\alpha=.76, M=2.71, S D=0.27$ ), and the Parental Control Scale (Cronbach's $\alpha=.66, M=1.64, S D=$ $0.30)$. On the day of the observation, parents completed the TenItem Personality Inventory (Extraversion: $M=4.26, S D=1.39$; Agreeableness: $M=4.09, S D=0.85$; Conscientiousness: $M=$ 4.47, $S D=1.07$; Emotional Stability: $M=4.02, S D=1.16$; Openness to Experience, $M=4.49, S D=0.96$ ).

Furthermore, children completed late-childhood versions of the seven-item Behavioral Inhibition System (BIS) scale (e.g., "I worry about making mistakes"; Cronbach's $\alpha=.70, M=1.36$, $S D=0.57$ ) and 13-item Behavioral Activation System (BAS) scale (e.g., "I get thrilled when good things happen to me"; Cronbach's $\alpha=.84, M=1.69, S D=0.53$; from $0=$ Not at all true to $3=$ Completely true; Muris, Meesters, de Kanter, \& Timmerman, 2005).

In-home observation. During the in-home observations, parents were instructed to administer mathematics exercises to their child (i.e., Exercises 5-16 from the Wechsler Intelligence Scale for Children-III; Wechsler, 1991). Parents were given a stopwatch and a score sheet, and judged whether the child correctly completed the exercise within $30 \mathrm{~s}$ (mean number of correct answers $=11.09$, $S D=1.06)$. Research assistants left the room until the exercises were completed, which took about $5 \mathrm{~min}$. The session was videotaped. Two trained coders, blind to parents' overvaluation scores, counted the number of times parents praised their child (agreement $=96 \%$ ).

\section{Results and Discussion}

Preliminary analyses. Replicating Studies 2 and 3, overvaluation was positively correlated with narcissism, $r(96)=.38, p<$ .001 . By contrast, overvaluation was unrelated to self-esteem, Big Five Traits, and parenting dimensions of warmth and control $(|.02|<r \mathrm{~s}<|.10|, p \mathrm{~s}>.338)$. Thus, unlike in Study 4, overvaluation was unrelated to warmth and Extraversion.

Child temperament. Parental overvaluation was unrelated to children's BIS and BAS, $r(100)=.03, p=.749$; and, $r(100)=-.06, p=.584$, respectively. ${ }^{5}$ This finding suggests that overvalued children are not different from other children in terms of their basic temperamental characteristics.

Unique names. We used a Dutch database (The Corpus of First Names in The Netherlands; Meertens Instituut, 2013) to obtain the annual frequency of the child's first name (i.e., the proportion of same-sex children born in the child's year of birth with the same first name as the child) in the Netherlands. For example, if Bob is a boy, and he was born in 2001, we coded the proportion of boys born in 2001 who received the name Bob. Because the database is confined to children born in the Netherlands and because it does not contain double names (e.g., "Klaas Jan"), parents whose child was born outside the Netherlands or had a double name were excluded from the analyses of first-name data $(n=7)$.

As predicted, overvaluation was correlated with unique, less common names in children, $r(94)=-.23, p=.025$. This relationship remained significant, albeit marginally, even when narcis- sism, self-esteem, Big Five traits, and parenting dimensions (warmth, control) were controlled for, $t(76)=-1.93, p=.058$, $b=-0.14, \beta=-.21$. This finding suggests that overvaluing parents want their child to stand out from others.

Praise. On average, parents praised their child 6.58 times $(S D=3.95)$. As predicted, overvaluation was correlated with a higher frequency of praise, $r(101)=.25, p=.011$, but was unrelated to children's number of correct answers, $r(101)=-.05$, $p=.654$. In fact, parents high $(+1 S D)$ in overvaluation praised their child $62 \%$ more often than did parents low $(-1 S D)$ in overvaluation. By contrast, narcissism, self-esteem, Big Five traits, and parenting dimensions (warmth, control) and children's number of correct answers were unrelated to frequency of praise $(|.07|<$ $r \mathrm{~s}<|.19|, p s>.055)$, and the association between overvaluation and praise remained significant even when these variables were controlled for, $t(82)=2.24, p=.028, b=1.91, \beta=.24$.

Thus, overvaluation predicts parents' tendency to praise their child in a real-life setting. Importantly, overvaluation was unrelated to children's actual performance in this setting.

\section{General Discussion}

Few of us would dispute that some parents hold unrealistically positive, inflated views of their children. To date, however, such parental overvaluation has rarely been studied as an individualdifference variable. We developed the POS to measure individual differences in parental overvaluation. Across six studies using multiple methods across two different cultures, we show that parental overvaluation can be measured reliably and validly using the POS. Parental overvaluation is related to parental narcissism, to parents' unrealistically positive views of their child, and to parents' desire for their child to stand out from others. In addition, it predicts parents' tendency to praise their child frequently. By contrast, parental overvaluation is not consistently related to parents' basic parenting dimensions (i.e., warmth and control) and Big Five personality traits. Together, these findings support the validity of the POS and demonstrate that parental overvaluation has important and unique implications for parents' beliefs and practices.

\section{Validity of the POS}

In Studies 1-4, we investigated the psychometric properties of the POS. The POS is a concise measure of stable individual differences in parental overvaluation. The scale has an internally consistent single-factor structure and high test-retest stability. Scores on the POS are relatively normally distributed, indicating

\footnotetext{
${ }^{5}$ We relied on child-reported temperament to prevent common method variance (Podsakoff, MacKenzie, Lee, \& Podsakoff, 2003) from affecting the association between parental overvaluation and child temperament. However, results for parent-reported child temperament are identical. Parents completed the Sensitivity to Punishment and Sensitivity to Reward Questionnaire for Children (Luman, van Meel, Oosterlaan, \& Geurts, 2012), which includes a 15-item BIS subscale (e.g., "Your child often worries about things he/she said or did"; Cronbach's $\alpha=.90, M=1.50$ $S D=0.72$ ) and a 19-item BAS subscale (e.g., "When your child gets something he/she wants, he/she feels excited and energized"; Cronbach's $\alpha=.83, M=1.72, S D=0.53$; from $0=$ Totally disagree to $4=$ Totally agree). Again, parental overvaluation was unrelated to children's BIS and BAS, $r(101)=-.15, p=.141$; and, $r(101)=.09, p=.372$, respectively
} 
that overvaluation is not uncommon or atypical-rather, overvaluation is a trait on which parents from the general population differ gradually from one another. Furthermore, in a representative sample of Dutch parents and a diverse sample of American parents, we explored the measurement invariance of the POS between boys and girls and between fathers and mothers. The POS showed strong measurement invariance in both studies, which means that the POS assesses the same latent construct regardless of child and parent sex. In Studies 3-6, we investigated the discriminant, convergent, and criterion validity of the POS. Attesting to its discriminant validity, the POS was largely unrelated to basic parenting dimensions and Big Five personality traits, with the possible exception of parental warmth and Extraversion. In addition, the POS was unrelated to children's intelligence, mathematics performance, and basic temperamental characteristics. Attesting to its convergent validity, the POS was associated with parental narcissism, with parents' perceptions of their child as superior to others, with their overclaiming of their child's knowledge, with their perceptions of their child as more gifted than actual IQ scores justify, and with children's unique, uncommon names. Attesting to its criterion validity, the POS predicted parents' tendency to frequently praise their child in a real-life setting.

\section{Theoretical Implications}

Our findings demonstrate pronounced individual differences in parental overvaluation. An important question is why some parents hold unrealistically positive-and therefore inaccurate-views of their children. We suggest that parental overvaluation might serve the purpose of self-enhancement. People have a pervasive motive to self-enhance (Sedikides, Gaertner, \& Vevea, 2005). However, blatant self-enhancement is often met with resistance; those who publicly claim their superiority are often disapproved by others (Leary, Bednarski, Hammon, \& Duncan, 1997). Overvaluation, however, might represent a concealed, more tactical attempt to self-enhance. Because children are often an important part of parents' selves (Brummelman et al., 2013), holding inflated views of children might represent an indirect means for parents to enhance themselves (cf. J. D. Brown \& Han, 2012; Masterson, 2000). Consistent with this view, our findings show that parental overvaluation is especially high in narcissistic parents. Narcissists are habitually inclined to enhance themselves (Morf \& Rhodewalt, 2001), and they might try to do so by holding inflated perceptions of their child's traits, behaviors, and accomplishments (N. W. Brown, 1998; Miller, 1981).

A large body of research shows that people often hold positive illusions about their significant others (e.g., Hall \& Taylor, 1976; Wenger \& Fowers, 2008). However, overvaluation might be especially high in parent-child relationships, for two reasons. First, parents often perceive their child as an important part of themselves (Brummelman et al., 2013). Given that parents always hold a genetic tie to their children, this psychological "unity" between parent and child is unlikely to dissolve. The more people regard others as part of themselves, the more likely they are to ascribe positive qualities to them (Martz et al., 1998). Second, parents often invest great effort in their child's upbringing. People place greater value on things they worked harder for (Aronson \& Mills, 1959). Previous work suggest that, similarly, the more effort parents invest in a child, the more they might come to overvalue this child (Cohen \& Fowers, 2004; cf. Eibach \& Mock, 2011).

\section{Strengths and Limitations}

We used rigorous methods in our research. We used a step-bystep approach to construct the POS, and we used stringent analyses to evaluate its factor structure and its measurement invariance in large samples of parents consisting of a well-balanced number of fathers and mothers from two different cultures. We explored the correlates of parental overvaluation using both questionnaires, novel unobtrusive behavioral measures, and observations of naturalistic parent-child interactions. We showed that the correlates of the POS are unique, and are not explained by basic parenting dimensions, narcissism, self-esteem, or Big Five personality traits. We assessed objective outcomes, such as IQ, to show that overvaluation does not result from objective competency differences between children. As such, our research represents a stringent and thorough examination of the validity of parental overvaluation.

Our research also has limitations. First, our data are correlational. An important task for future research is to use experimental and longitudinal methods to unravel the antecedents and consequences of parental overvaluation. Does parental narcissism predict increases in overvaluation over time? And is this mediated by parents' self-enhancement motives? Can parental overvaluation be temporarily increased (e.g., by having parents reflect on what makes their child stand out from others)? And does such increased overvaluation lead parents to praise their children more frequently?

Second, we chose to study parents of children in late childhood-a time when individual differences in parental overvaluation might be relatively large, and when parental overvaluation might be especially consequential for children's self-views and behaviors. Thus, the generalizability of the study findings to parents of children of other ages remains unknown. Interesting questions are whether the level and the consequences of overvaluation change over the course of children's development. Overvaluation may be especially high when children are young, when parents' beliefs about their child's qualities have not yet been tested against reality (Wenger \& Fowers, 2008). Overvaluation may be especially consequential in older children, who readily internalize others' views of them, and who seek to live up to these views (Harter, 2012). Addressing these questions is important for understanding overvaluation and its consequences within children's developmental context.

Third, another question that remains is whether overvalued children have certain characteristics that make them more likely to be overvalued by their parents. Our studies included objective criteria (i.e., IQ tests) and demonstrate that overvalued children are not more intelligent (Study 5) or better performing (Study 6) than other children, although their parents believe they are. In addition, overvalued children do not differ from other children in terms of their basic temperamental characteristics (Study 6). However, a limitation of our research is that it does not rule out that overvalued children have certain nonintellectual skills (e.g., charm) that make them more "valuable" in parents' eyes. Future research should examine this interesting possibility. 


\section{New Research Directions}

By delineating the construct of parental overvaluation, the present research opens up new avenues for future research. One important direction is to examine how parental overvaluation affects children's development. Children readily internalize their parents' views of them (Cooley, 1902; Harter, 2012). On the basis of this idea, theorists and clinicians have long viewed parental overvaluation as an important cause of narcissism (for an overview, see Thomaes \& Brummelman, in press). Narcissistic children believe they are superior to others and feel more entitled than others, yet at the same time crave other people's admiration to feel good about themselves (Morf \& Rhodewalt, 2001; Thomaes, Stegge, Bushman, Olthof, \& Denissen, 2008). According to social-learning perspectives, parental overvaluation conveys to children that they are superior to others, and that they deserve special treatment and praise (Imbesi, 1999; Millon, 1969, 2011). Our findings confirm, in a naturalistic setting, that overvaluation predicts parental praise. Although seemingly benign, praise can backfire (Brummelman et al., 2014; Brummelman, Thomaes, Overbeek, et al., 2014; Mueller \& Dweck, 1998). In fact, praise might have addictive qualities (Baumeister \& Vohs, 2001; Bushman, Moeller, \& Crocker, 2011). Over the course of development, children who are overvalued by their parents might become dependent on such external validation to feel worthy (Thomaes, Brummelman, Reijntjes, \& Bushman, 2013; Thomaes, Bushman, Orobio de Castro, \& Stegge, 2009). Parental overvaluation may thus foster core characteristics of narcissism in children.

Preliminary evidence is consistent with this prediction. A correlational study revealed that adult narcissism was related to self-reported recollections of parental overvaluation (Otway \& Vignoles, 2006). However, this study is retrospective and correlational, and it exclusively relied on self-report. It is perhaps not surprising that adult narcissists report that their parents admired them - they typically feel admired by many people (Morf \& Rhodewalt, 2001; Rhodewalt \& Eddings, 2002). What is needed is prospective longitudinal research tracking the bidirectional associations between parent-reported parental overvaluation and child-reported narcissism over time in childhood.

Another interesting research direction is to examine whether overvaluation differs between parent-child dyads within the same family. Do parents who overvalue one child also overvalue their other children? Or do they target their overvaluation at one child in particular, perhaps as a function of children's birth order? It is well documented that parents often favor one child over their other children (for an overview, see Suitor et al., 2008). First-born and last-born children are especially likely to be favored by their parents (Hertwig, Davis, \& Sulloway, 2002). When overvaluation is directed at one child in particular and fosters comparisons among siblings, it might function as a double-edged sword: It might instill in the "favorite" a sense of superiority, yet in his or her siblings a sense of inferiority. Future research might shed light on these possible within-family dynamics.

Our research focused on parents from Western, individualistic cultures. Future research should examine the cultural specificity of parental overvaluation. One possibility is that parental overvaluation is higher in Western than non-Western cultures. Although the motive to self-enhance is probably universal, people from Western cultures self-enhance more on individualistic traits, such as standing out from others (Sedikides, Gaertner, \& Vevea, 2005). Overvaluing their children might be one means for Western parents to stand out from others.
Another possibility is that parental overvaluation is higher in nonWestern than Western cultures. Relationships are more self-defining in non-Western cultures (Markus \& Kitayama, 1991). For example, Chinese mothers' feelings of worth are more contingent upon children's academic performance than are those of European or African American mothers (Ng, Pomerantz, \& Deng, 2013). Thus, especially in non-Western cultures, overvaluing children might make parents feel of worth.

\section{Conclusions}

Some parents consider their child to be "God's gift to humanity." Although pervasive in everyday life and psychological theory, parental overvaluation has rarely been empirically studied as an individualdifference variable. Our research introduces a concise self-report measure of parental overvaluation, the POS. Our findings show that overvaluation is especially high in narcissistic parents and that overvaluation has important implications for parenting beliefs and practices that are not captured by existing parenting measures. Thus, our research sheds novel light on the nature, measurement, and correlates of parental overvaluation. We hope that our research will inspire researchers to study parental overvaluation and to unravel its impact on parents' and children's lives.

\section{References}

Alicke, M. D., Klotz, M. L., Breitenbecher, D. L., Yurak, T. J., \& Vredenburg, D. S. (1995). Personal contact, individuation, and the betterthan-average effect. Journal of Personality and Social Psychology, 68 , 804-825. doi:10.1037/0022-3514.68.5.804

Ames, D. R., Rose, P., \& Anderson, C. P. (2006). The NPI-16 as a short measure of narcissism. Journal of Research in Personality, 40, 440450. doi:10.1016/j.jrp.2005.03.002

Aron, A., \& Aron, E. N. (1986). Love and the expansion of self: Understanding attraction and satisfaction. New York, NY: Hemisphere.

Aronson, E., \& Mills, J. (1959). The effect of severity of initiation on liking for a group. Journal of Abnormal and Social Psychology, 59, 177-181. doi:10.1037/h0047195

Barelds-Dijkstra, P., \& Barelds, D. P. (2008). Positive illusions about one's partner's physical attractiveness. Body Image, 5, 99-108. doi:10.1016/ j.bodyim.2007.07.004

Baumeister, R. F., \& Vohs, K. D. (2001). Narcissism as addiction to esteem. Psychological Inquiry, 12, 206-210. doi:10.1207/ S15327965PLI1204_2

Brown, J. D., \& Han, A. (2012). My better half: Partner enhancement as self-enhancement. Social Psychological and Personality Science, 3, 479-486. doi:10.1177/1948550611427607

Brown, N. W. (1998). The destructive narcissistic pattern. Westport, CT: Praeger.

Brummelman, E., Thomaes, S., Orobio de Castro, B., Overbeek, G., \& Bushman, B. J. (2014). "That's not just beautiful-That's incredibly beautiful!": The adverse impact of inflated praise on children with low self-esteem. Psychological Science, 25, 728-735. doi:10.1177/ 0956797613514251

Brummelman, E., Thomaes, S., Overbeek, G., Orobio de Castro, B., van den Hout, M. A., \& Bushman, B. J. (2014). On feeding those hungry for praise: Person praise backfires in children with low self-esteem. Journal of Experimental Psychology: General, 143, 9-14. doi:10.1037/ a0031917

Brummelman, E., Thomaes, S., Slagt, M. I., Overbeek, G., Orobio de Castro, B., \& Bushman, B. J. (2013). My child redeems my broken dreams: On parents transferring their unfulfilled ambitions onto their child. Plos ONE, 8, e65360. doi:10.1371/journal.pone.0065360 
Bukowski, W. M., Schwartzman, A., Santo, J., Bagwell, C., \& Adams, R. (2009). Reactivity and distortions in the self: Narcissism, types of aggression, and the functioning of the hypothalamic-pituitary-adrenal axis during early adolescence. Development and Psychopathology, 21, 1249-1262. doi:10.1017/S0954579409990149

Bushman, B. J., Moeller, S. J., \& Crocker, J. (2011). Sweets, sex, or self-esteem? Comparing the value of self-esteem boosts with other pleasant rewards. Journal of Personality, 79, 993-1012. doi:10.1111/j .1467-6494.2011.00712.x

Campbell, W. K., Bonacci, A. M., Shelton, J., Exline, J. J., \& Bushman, B. J. (2004). Psychological entitlement: Interpersonal consequences and validation of self-report measure. Journal of Personality Assessment, 83, 29-45. doi:10.1207/s15327752jpa8301_04

Cialdini, R. B., Borden, R. J., Thorne, A., Walker, M. R., Freeman, S., \& Sloan, L. R. (1976). Basking in reflected glory: Three (football) field studies. Journal of Personality and Social Psychology, 34, 366-375. doi: $10.1037 / 0022-3514.34 .3 .366$

Clark, L. A., \& Watson, D. (1995). Constructing validity: Basic issues in objective scale development. Psychological Assessment, 7, 309-319. doi:10.1037/1040-3590.7.3.309

Cohen, J. D., \& Fowers, B. J. (2004). Blood, sweat, and tears: Biological ties and self-investment as sources of positive illusions about children and stepchildren. Journal of Divorce and Remarriage, 42, 39-59. doi: 10.1300/J087v42n01_02

Collins, W. A., Madsen, S. D., \& Susman-Stillman, A. (2002). Parenting during middle childhood. In M. H. Bornstein (Ed.), Handbook of parenting: Volume I, children and parenting (pp. 73-101). Mahwah, NJ: Lawrence Erlbaum.

Cooley, C. H. (1902). Human nature and the social order. New York, NY: Scribner's.

Costello, A. B., \& Osborne, J. W. (2005). Best practices in exploratory factor analysis: Four recommendations for getting the most from your analysis. Practical Assessment, Research, and Evaluation, 10, 1-5.

Darling, N., \& Steinberg, L. (1993). Parenting style as context: An integrative model. Psychological Bulletin, 113, 487-496. doi:10.1037/00332909.113.3.487

Depue, R. A., \& Collins, P. F. (1999). Neurobiology of the structure of personality: Dopamine, facilitation of incentive motivation, and extraversion. Behavioral and Brain Sciences, 22, 491-517. doi:10.1017/ S0140525X99002046

Eibach, R. P., \& Mock, S. E. (2011). Idealizing parenthood to rationalize parental investments. Psychological Science, 22, 203-208. doi:10.1177/ 0956797610397057

Elliot, A. J., \& Thrash, T. M. (2002). Approach-avoidance motivation in personality: Approach and avoidance temperaments and goals. Journal of Personality and Social Psychology, 82, 804-818. doi:10.1037/00223514.82.5.804

Finch, J. (2008). Naming names: Kinship, individuality and personal names. Sociology, 42, 709-725. doi:10.1177/0038038508091624

Freud, S. (1957). On narcissism: An introduction. In J. Strachey (Ed.), The standard edition of the complete psychological works of Sigmund Freud (Vol. 14, pp. 73-102). London, England: Hogarth Press. (Original work published 1914)

Gosling, S. D., Rentfrom, P. J., \& Swann, W. B., Jr. (2003). A very brief measure of the Big-Five personality domains. Journal of Research in Personality, 37, 504-528. doi:10.1016/S0092-6566(03)00046-1

Hall, J. A., \& Taylor, S. E. (1976). When love is blind: Maintaining idealized images of one's spouse. Human Relations, 29, 751-761. doi: $10.1177 / 001872677602900804$

Harter, S. (2012). Construction of the self: Developmental and sociocultural foundations. New York, NY: Guilford Press.

Henderlong, J., \& Lepper, M. (2002). The effects of praise on children's intrinsic motivation: A review and synthesis. Psychological Bulletin, 128, 774-795. doi:10.1037/0033-2909.128.5.774
Hertwig, R., Davis, J. N., \& Sulloway, F. J. (2002). Parental investment: How an equity motive can produce inequality. Psychological Bulletin, 128, 728-745. doi:10.1037/0033-2909.128.5.728

Hirsch, E. D., Jr. (Ed.). (2004). The new first dictionary of cultural literacy. What your child needs to know. New York, NY: Houghton Mifflin.

Horney, K. (1939). New ways in psychoanalysis. New York, NY: Norton.

Hu, L.-T., \& Bentler, P. M. (1999). Cutoff criteria for fit indexes in covariance structure analysis: Conventional criteria versus new alternatives. Structural Equation Modeling, 6, 1-55. doi:10.1080/ 10705519909540118

Imbesi, L. (1999). The making of a narcissist. Clinical Social Work Journal, 27, 41-54. doi:10.1023/A:1022809314267

Kames, H. (1788). Elements of criticism (7th ed., Vol. 1). Edinburgh, England: Bell and Creech. (Original work published 1762)

Kanouse, D. E., Gumpert, P., \& Canavan-Gumpert, D. (1981). The semantics of praise. In J. H. Harvey, W. Ickes, \& R. F. Kidd (Eds.), New directions in attribution research (Vol. 3, pp. 97-115). Hillsdale, NJ: Erlbaum.

Kernberg, O. F. (1975). Borderline conditions and pathological narcissism. New York, NY: Jason Aronson.

Kline, R. B. (2005). Principles and practice of structural equation modeling (2nd ed.). New York, NY: Guilford Press.

Krebs, D. L., \& Denton, K. (1997). Social illusions and self-deception: The evolution of biases in person perception. In J. A. Simpson \& T. Douglas (Eds.), Evolutionary social psychology (pp. 21-48). Mahwah, NJ: Lawrence Erlbaum.

Leary, M. R., Bednarski, R., Hammon, D., \& Duncan, T. (1997). Blowhards, snobs, and narcissists: Interpersonal reactions to excessive egotism. In R. M. Kowalski (Ed.), Aversive interpersonal behaviors (pp. 111-131). New York, NY: Plenum. doi:10.1007/978-1-4757-9354-3_6

Luman, M., van Meel, C. S., Oosterlaan, J., \& Geurts, H. M. (2012). Reward and punishment sensitivity in children with ADHD: Validating the Sensitivity to Punishment and Sensitivity to Reward Questionnaire for children (SPSRQ-C). Journal of Abnormal Child Psychology, 40, 145-157. doi:10.1007/s10802-011-9547-x

Maccoby, E. E. (1984). Middle childhood in the context of the family. In W. A. Collins (Ed.), Development during middle childhood: The years from six to twelve (pp. 184-239). Washington, DC: National Academy of Sciences.

Macmillan, N. A., \& Creelman, C. D. (2005). Signal detection theory: A user's guide (2nd ed.). Mahwah, NJ: Erlbaum.

Macmillan, N. A., \& Kaplan, H. L. (1985). Detection theory analysis of group data: Estimating sensitivity from average hit and false-alarm rates. Psychological Bulletin, 98, 185-199. doi:10.1037/0033-2909.98.1.185

Markus, H. R., \& Kitayama, S. (1991). Culture and the self: Implications for cognition, emotion, and motivation. Psychological Review, 98, 224 253. doi: $10.1037 / 0033-295 X .98 .2 .224$

Martz, J. M., Verette, J., Arriaga, X. B., Slovik, L. F., Cox, C. L., \& Rusbult, C. E. (1998). Positive illusion in close relationships. Personal Relationships, 5, 159-181. doi:10.1111/j.1475-6811.1998.tb00165.x

Masterson, J. F. (2000). The personality disorders: A new look at the developmental self and object relations approach: Theory, diagnosis, treatment. Phoenix, AZ: Zeig, Tucker \& Co.

Meertens Instituut. (2013). The corpus of first names in the Netherlands. Retrieved from http://www.meertens.knaw.nl/nvb/english

Miller, A. (1981). Prisoners of childhood. New York, NY: Basic Books.

Millon, T. (1969). Modern psychopathology: A biosocial approach to maladaptive learning and functioning. Philadelphia, PA: Saunders.

Millon, T. (2011). Disorders of personality: Introducing a DSM/ICD spectrum from normal to abnormal (3rd ed.). Hoboken, NJ: John Wiley \& Sons. doi:10.1002/9781118099254

Morf, C. C., \& Rhodewalt, F. (2001). Unraveling the paradoxes of narcissism: A dynamic self-regulatory processing model. Psychological Inquiry, 12, 177-196. doi:10.1207/S15327965PLI1204_1 
Mueller, C. M., \& Dweck, C. S. (1998). Praise for intelligence can undermine children's motivation and performance. Journal of Personality and Social Psychology, 75, 33-52. doi:10.1037/0022-3514.75.1.33

Muris, P., Meesters, C., de Kanter, E., \& Timmerman, P. E. (2005). Behavioural inhibition and behavioural activation system scales for children: Relationships with Eysenck's personality traits and psychopathological symptoms. Personality and Individual Differences, 38, 831-841. doi:10.1016/j.paid.2004.06.007

Murray, S. L., \& Holmes, J. G. (1997). A leap of faith? Positive illusions in romantic relationships. Personality and Social Psychology Bulletin, 23, 586-604. doi:10.1177/0146167297236003

Murray, S. L., Holmes, J. G., \& Griffin, D. W. (1996). The self-fulfilling nature of positive illusions in romantic relationships: Love is not blind, but prescient. Journal of Personality and Social Psychology, 71, 11551180. doi:10.1037/0022-3514.71.6.1155

Muthén, B. O. (2004). Mplus technical appendices. Los Angeles, CA: Muthén \& Muthén.

Muthén, L. K., \& Muthén, B. O. (2012). Mplus user's guide (7th ed.). Los Angeles, CA: Author.

Ng, F. F.-Y., Pomerantz, E. M., \& Deng, C. (2014). Why are Chinese mothers more controlling than American mothers? "My child is my report card". Child Development, 85, 355-369. doi:10.1111/cdev.12102

Otway, L. J., \& Vignoles, V. L. (2006). Narcissism and childhood recollections: A quantitative test of psychoanalytic predictions. Personality and Social Psychology Bulletin, 32, 104-116. doi:10.1177/ 0146167205279907

Paulhus, D. L., Harms, P. D., Bruce, M. N., \& Lysy, D. C. (2003). The over-claiming technique: Measuring bias independent of accuracy. Journal of Personality and Social Psychology, 84, 681-693. doi:10.1037/ 0022-3514.84.4.890

Paulhus, D. L., \& Holden, R. R. (2010). Measuring self-enhancement: From self-report to concrete behavior. In C. R. Agnew, D. E. Carlston, W. G. Graziano, \& J. R. Kelly (Eds.), Then a miracle occurs: Focusing on behavior in social psychological theory and research (pp. 227-246). New York, NY: Oxford University Press.

Podsakoff, P. M., MacKenzie, S. B., Lee, J. Y., \& Podsakoff, N. P. (2003). Common method biases in behavioral research: A critical review of the literature and recommended remedies. Journal of Applied Psychology, 88, 879-903. doi:10.1037/0021-9010.88.5.879

Rhodewalt, F., \& Eddings, S. K. (2002). Narcissus reflects: Memory distortion in response to ego-relevant feedback among high-and lownarcissistic men. Journal of Research in Personality, 36, 97-116. doi: 10.1006/jrpe.2002.2342

Rohner, R. P. (2005a). Parental Acceptance-Rejection Questionnaire (PARQ): Test manual. In R. P. Rohner \& A. Khaleque (Eds.), Handbook for the study of parental acceptance and rejection (4th ed., pp. 43-106). Storrs, CT: Rohner Research.

Rohner, R. P. (2005b). Parental Control Scale (PCS): Test manual. In R. P. Rohner \& A. Khaleque (Eds.), Handbook for the study of parental acceptance and rejection (4th ed., pp. 107-135). Storrs, CT: Rohner Research.

Rosenberg, M. (1965). Society and the adolescent self-image. Princeton, NJ: Princeton University Press.

Rothbart, M. K., Ahadi, S. A., \& Evans, D. E. (2000). Temperament and personality: Origins and outcomes. Journal of Personality and Social Psychology, 78, 122-135. doi:10.1037/0022-3514.78.1.122

Sedikides, C., Gaertner, L., \& Vevea, J. L. (2005). Pancultural selfenhancement reloaded: A meta-analytic reply to Heine (2005). Journal of Personality and Social Psychology, 89, 539-551. doi:10.1037/00223514.89.4.539

Selman, R. L. (1980). The growth of interpersonal understanding: Developmental and clinical analyses. New York, NY: Academic Press.

Stanislaw, H., \& Todorov, N. (1999). Calculation of signal detection theory measures. Behavior Research Methods, Instruments, \& Computers, 31 , 137-149. doi:10.3758/BF03207704

Suitor, J. J., Sechrist, J., Plikuhn, M., Pardo, S. T., \& Pillemer, K. (2008) Within-family differences in parent-child relations across the life course Current Directions in Psychological Science, 17, 334-338. doi:10.1111/ j.1467-8721.2008.00601.x

Thomaes, S., \& Brummelman, E. (in press). Narcissism. In D. Cicchetti (Ed.), Developmental psychopathology (Vol. 4, 3rd ed.). Hoboken, NJ Wiley.

Thomaes, S., Brummelman, E., Reijntjes, A., \& Bushman, B. J. (2013) When Narcissus was a boy: Origins, nature, and consequences of childhood narcissism. Child Development Perspectives, 7, 22-26. doi: 10.1111/cdep.12009

Thomaes, S., Bushman, B. J., Orobio de Castro, B., \& Stegge, H. (2009) What makes narcissists bloom? A framework for research on the etiology and development of narcissism. Development and Psychopathology, 21, 1233-1247. doi:10.1017/S0954579409990137

Thomaes, S., Bushman, B. J., Stegge, H., \& Olthof, T. (2008). Trumping shame by blasts of noise: Narcissism, self-esteem, shame, and aggression in young adolescents. Child Development, 79, 1792-1801. doi: 10.1111/j.1467-8624.2008.01226.x

Thomaes, S., Stegge, H., Bushman, B. J., Olthof, T., \& Denissen, J. (2008), Development and validation of the Childhood Narcissism Scale Journal of Personality Assessment, 90, 382-391. doi:10.1080/ 00223890802108162

Trapnell, P. D., \& Paulhus, D. L. (2012). Agentic and communal values: Their scope and measurement. Journal of Personality Assessment, 94, 39-52. doi:10.1080/00223891.2011.627968

Twenge, J. M. (2006). Generation me: Why today's young Americans are more confident, assertive, entitled-And more miserable than ever before. New York, NY: Free Press.

Twenge, J. M., Abebe, E. M., \& Campbell, W. K. (2010). Fitting in or standing out: Trends in American parents' choices for children's names, 1880-2007. Social Psychological and Personality Science, 1, 19-25. doi:10.1177/1948550609349515

Vandenberg, R. J., \& Lance, C. E. (2000). A review and synthesis of the measurement invariance literature: Suggestions, practices, and recommendations for organizational research. Organizational Research Methods, 3, 4-70. doi:10.1177/109442810031002

van Dijk, H., \& Tellegen, P. J. (2004). NIO Nederlandse Intelligentietest voor Onderwijsniveau [Dutch Intelligence test for Educational Level]. Amsterdam, the Netherlands: Boom.

Varnum, M. E., \& Kitayama, S. (2011). What's in a name? Popular names are less common on frontiers. Psychological Science, 22, 176-183. doi:10.1177/0956797610395396

Wechsler, D. (1991). Wechsler Intelligence Scale for Children (3rd ed.). San Antonio, TX: Psychological Corporation.

Wenger, A., \& Fowers, B. J. (2008). Positive illusions in parenting: Every child is above average. Journal of Applied Social Psychology, 38, 611-634. doi:10.1111/j.1559-1816.2007.00319.x

Young-Eisendrath, P. (2008). The self-esteem trap: Raising confident and compassionate kids in an age of self-importance. New York, NY: Little, Brown. 


\section{Appendix A}

\section{Parental Overvaluation Scale}

Here are a number of statements describing ways in which parents can think about their child. Please indicate for each statement how well it describes the way you think about your child.

1. Without my child, his/her class would be much less fun.

2. My child deserves special treatment.

3. I would not be surprised to learn that my child has extraordinary talents and abilities.

4. I would find it disappointing if my child was just a "regular" child.
5. My child is more special than other children.

6. My child deserves something extra in life.

7. My child is a great example for other children to follow.

Note. $\quad$ Responses are scored on 4-point Likert-scales $(0=$ Not at all true,

$1=$ Not really true, $2=$ Sort of true, $3=$ Completely true $)$. The Dutch version of the Parental Overvaluation Scale can be obtained from the first author.

\section{Appendix B}

\section{My Child Versus Other Children Scale}

Please write the number of the diagram (1-7) that best represents how you see your child "M" compared to other children "O"?

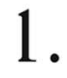

0<smiles></smiles>

4.

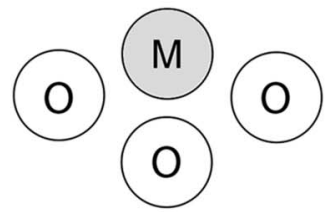

2.<smiles>c1ccccc1</smiles><smiles></smiles>

5.
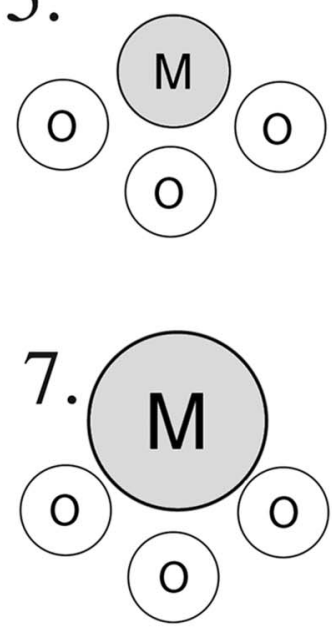

3.
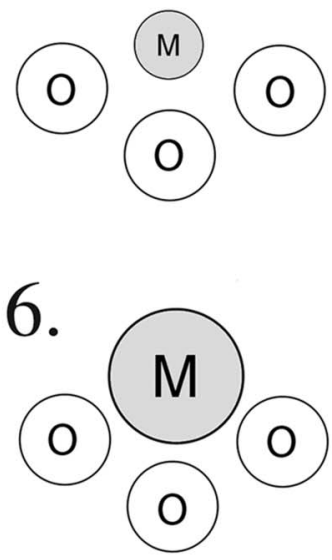


\section{Appendix C}

\section{Parental Overclaiming Questionnaire}

Please estimate your child's familiarity with these terms $(0=$ Never heard of $i t ; 1=$ Little familiar; $2=$ Somewhat familiar; $3=$ Quite familiar; 4 = Very familiar). The questions address your estimation of your child's familiarity with terms, so please don't check answers with your child. ${ }^{*}=$ foils).

\begin{tabular}{|c|c|c|c|}
\hline Historical events & Historical figures & World geography & Literature \\
\hline 1. French Revolution & 21. Winston Churchill & 41. Balkans & 61. Sherlock Holmes \\
\hline 2. Beijing Revolution* & 22. Franklin D. Roosevelt & 42. Cape of Good Hope & 62. Animal Farm \\
\hline 3. Great Depression & 23. Neil Armstrong & 43. Baltic Sea & 63. The Blind Men and the Elephant \\
\hline 4. Renaissance & 24. Nelson Amrabat* & 44. Yugoslavia & 64. Odyssey \\
\hline 5. Seventy Years' War* & 25. Anne Frank & 45. Sicilian River* & 65. The Sunny Garden* \\
\hline 6. Vietnam War & 26. Fidel Castro & 46. Istanbul & 66. The Legend of Sleepy Hollow \\
\hline 7. German War on Independence* & 27. George-William IIV* & 47. Ljungberg* & 67. The Princess and the Grapes* \\
\hline 8. Battle of Waterloo & 28. Mahatma Gandhi & 48. Berlin & 68. Lord of the Flies \\
\hline 9. Concentration camp & 29. Alexander the Great & 49. Oslo & 69. Doctor Fehr* \\
\hline 10. The Fall of the French Dynasty* & 30. Queen Alberta* & 50. The Green Sea* & 70. Arabian Nights \\
\hline 11. World War I & 31. Lenin & 51. Gobi Dessert & 71. Rip van Winkle \\
\hline 12. Cold War & 32. Miguel Alvaro* & 52. Cyprus & 72. The Catcher in the Rye \\
\hline 13. Gulf War & 33. Mussolini & 53. Mont Blanc & 73. The Owl and the Spider* \\
\hline 14. Civil Rights Movement & 34. Emiliano Zapata & 54. Colombia & 74. Charlotte's Web \\
\hline 15. Holocaust & 35. Brutus & 55. Gaza Strip & 75. Don Quixote \\
\hline 16. D-Day & 36. Ivan the Terrible & 56. The Great Mountains* & 76. The Goose That Laid the Golden Eggs \\
\hline 17. Reformation & 37. Kidd Captain & 57. Caspian Sea & 77. The Wind in the Willows \\
\hline 18. Manhattan Project & 38. El Puente* & 58. Black Sea & 78. The Wonderful Wizard of $\mathrm{Oz}$ \\
\hline 19. Storming of Austria* & 39. Captain James Cook & 59. Albania & 79. Pollyanna \\
\hline 20. Apartheid & 40. Oliver Cromwell & 60. Russian Passage* & 80. The Tale of Benson Bunny* \\
\hline
\end{tabular}

Received December 7, 2013

Revision received March 31, 2014

Accepted April 2, 2014 